\title{
Effects of isomalt consumption on gastrointestinal and metabolic parameters in healthy volunteers
}

\author{
A. Gostner ${ }^{1}$, V. Schäffer ${ }^{1}$, S. Theis ${ }^{2}$, T. Menzel ${ }^{1}$, H. Lührs ${ }^{1}$, R. Melcher ${ }^{1}$, J. Schauber ${ }^{1}$, T. Kudlich ${ }^{1}$, G. Dusel ${ }^{1}$, \\ D. Dorbath ${ }^{1}$, G. Kozianowski ${ }^{2}$ and W. Scheppach ${ }^{1}$ \\ ${ }^{1}$ Department of Medicine, University of Würzburg, Josef-Schneider-Strasse 2, D-97080 Würzburg, Germany \\ ${ }^{2}$ SUEDZUCKER AG, Wormser Strasse 11, D-67283 Obrigheim/Pfalz, Germany
}

(Received 21 October 2004 - Revised 14 March 2005 - Accepted 21 April 2005)

\begin{abstract}
The polyol isomalt (Palatinit ${ }^{\circledR}$ ) is a well established sugar replacer. The impact of regular isomalt consumption on metabolism and parameters of gut function in nineteen healthy volunteers was examined in a randomised, double-blind, cross-over trial with two 4-week test periods. Volunteers received $30 \mathrm{~g}$ isomalt or $30 \mathrm{~g}$ sucrose daily as part of a controlled diet. In addition to clinical standard diagnostics, biomarkers and parameters currently discussed as risk factors for $\mathrm{CHD}$, diabetes or obesity were analysed. Urine and stool $\mathrm{Ca}$ and phosphate excretions were measured. In addition, mean transit time, defecation frequency, stool consistency and weight were determined. Consumption of test products was affirmed by the urinary excretion of mannitol. Blood lipids were comparable in both phases, especially in volunteers with hyperlipidaemia, apart from lower apo A-1 ( $P=0 \cdot 03$ ) for all subjects. Remnant-like particles, oxidised LDL, NEFA, fructosamine and leptin were comparable and not influenced by isomalt. Ca and phosphate homeostasis was not affected. Stool frequency was moderately increased in the isomalt phase $(P=0 \cdot 006)$ without changes in stool consistency and stool water. This suggests that isomalt is well tolerated and that consumption of isomalt does not impair metabolic function or induce hypercalciuria. In addition, the study data indicate that isomalt could be useful in improving bowel function.
\end{abstract}

Isomalt: Metabolic parameters: Stool parameters: Healthy volunteers

The polyol isomalt (Palatinit ${ }^{\circledR}$ ) is a well established sugar replacer with low physiological energy value (approximately $8.4 \mathrm{~kJ} / \mathrm{g}$; Livesey et al. 2000) that is non-cariogenic (Gehring \& Karle, 1981) and has low glycaemic properties in diabetics (Petzoldt et al. 1982; Gee et al. 1991; Hütter et al. 1993).

Chemically, isomalt is a mixture of the polyols $1-O-\alpha-\mathrm{D}$-glucopyranosyl-D-mannitol (GPM) and 6- $O$ - $\alpha$-D-glucopyranosyl-D-sorbitol (GPS). It is derived from sucrose in two major processing steps: (i) the enzymatic rearrangement of sucrose (2-O- $\alpha$-D-glucopyranosyl-D-fructofuranose) into isomaltulose (palatinose; $6-O-\alpha-$ D-glucopyranosyl-D-fructofuranose) and (ii) the catalytic hydrogenation of isomaltulose into isomalt (Fig. 1). In the upper digestive tract isomalt is only slowly and incompletely hydrolysed to glucose, sorbitol and mannitol (Dills, 1989). Released glucose is actively absorbed, whereas sorbitol and mannitol are partially absorbed from the small intestinal lumen. Absorbed glucose and sorbitol are further metabolised in the liver whereas most of the absorbed mannitol is excreted unchanged in urine (Life Science Research Office, 1994). As reviewed by Livesey (2003), as a consensus approximately $90 \%$ of ingested isomalt reaches the colon and is completely fermented by the gut microflora to gases and SCFA (Bär, 1990).

Like other low-digestible carbohydrates such as resistant starch, NSP such as inulin and non-digestible oligosaccharides such as fructo-oligosaccharides, isomalt provides substrates for microbial fermentation and therefore has potential prebiotic properties. It is speculated that chronic consumption of low-digestible carbohydrates may be protective against Western diseases like CHD, metabolic syndrome and bowel function disorders (Scheppach et al. 2001).

Owing to its potential prebiotic and non-prebiotic beneficial health effects, isomalt may be a promising 'functional food' component with technological properties comparable to sucrose. Various studies have been conducted in man to investigate tolerance (Zumbe \& Brinkworth, 1992; Koutsou et al. 1996; Lee et al. 2002; Storey et al. 2002) and glycaemic response (Petzoldt et al. 1982; Gee et al. 1991; Hütter et al. 1993). Typically, isomalt and other polyols are well tolerated apart from excessive intakes (Livesey, 2001). However, little is known about effects of longer isomalt consumption on other metabolic parameters and gut function in man.

The objective of the present study was to investigate health aspects of isomalt intake in normolipidaemic and hyperlipidaemic volunteers. Several of the investigated parameters are currently discussed as risk factors for common Western diseases like diabetes mellitus, CVD and chronic functional constipation.

\section{Subjects and methods}

Subjects and study design

Twenty healthy volunteers were recruited for the trial. Nineteen volunteers, aged 21-53 years (median 30.5 years), completed 


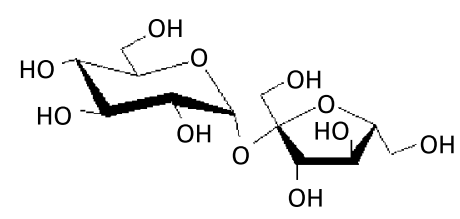

Sucrose

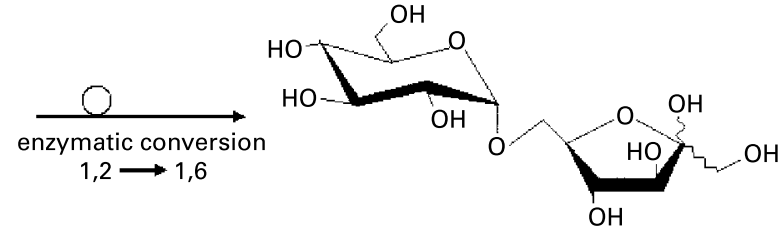

Isomaltulose (palatinose)

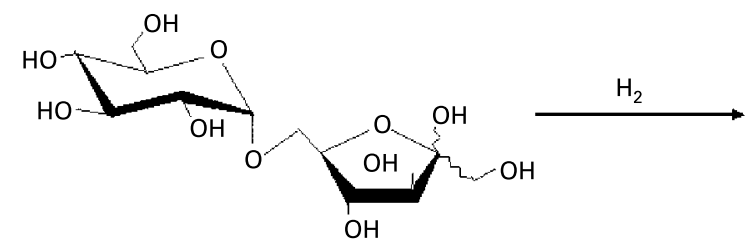

Isomaltulose

(palatinose)

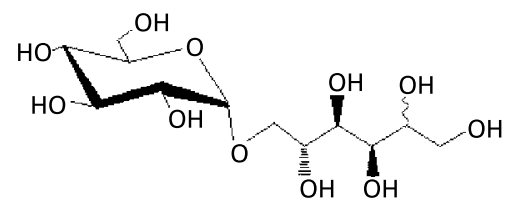

Isomalt

(GPM, GPS)

Fig. 1. Production of isomalt. GPM, 1-O- $\alpha$-D-glucopyranosyl-D-mannitol; GPS, 6-O- $\alpha$-D-glucopyranosyl-D-sorbitol.

the study (twelve women and seven men). One volunteer dropped out because of febrile tonsillitis, which had to be treated with antibiotics (exclusion criterion). Prior to entry, subjects were screened for their blood lipid status. Six of the participants were considered hyperlipidaemic with baseline cholesterol level $>220 \mathrm{mg} / \mathrm{dl}$ and/ or triacylglycerol level $>172 \mathrm{mg} / \mathrm{dl}$. Intake of antibiotics, laxatives, motility-affecting or lipid-altering medications was not allowed during the study. Intake of antibiotics more than 6 weeks prior to the start of the study was tolerated. Other exclusion criteria were history of severe chronic medical disease, including gastrointestinal diseases; severe abdominal discomfort; severe constipation; unusual dietary habits; known or suspected lack of compliance with the study protocol; and pathologic clinical parameters (apart from increased blood lipids). All participants signed informed consent forms after written and oral information about aim, course, and potential hazards of the trial. The study was approved by the Ethics Committee of the Faculty of Medicine, University of Würzburg, Germany.

During the two 4-week study periods, volunteers consumed a controlled diet. The diets were virtually isoenergetic (difference in energy intake approximately $200 \mathrm{~kJ} / \mathrm{d}$ ) and composed as a typical Western diet (low-fibre, high-fat). They provided $46 \%$ of energy as carbohydrate, $40 \%$ of energy as fat, and $14 \%$ of energy as protein (Table 1). The diets were identical except that

Table 1. Composition of the study diet

(Mean values with their standard error)

\begin{tabular}{|c|c|c|c|c|}
\hline & \multicolumn{2}{|c|}{ Women (n 12) } & \multicolumn{2}{|c|}{ Men $(n 7)$} \\
\hline & Mean & SE & Mean & SE \\
\hline Estimated energy (MJ) & 8.8 & 0.1 & $11 \cdot 3$ & 0.1 \\
\hline Carbohydrate (\% of energy) & $46 \cdot 0$ & 3.5 & $46 \cdot 1$ & $1 \cdot 8$ \\
\hline Protein (\% of energy) & 14.4 & 1.5 & $14 \cdot 1$ & $1 \cdot 2$ \\
\hline Fat (\% of energy) & $39 \cdot 4$ & $2 \cdot 4$ & 39.7 & $1 \cdot 1$ \\
\hline Dietary fibre $(\mathrm{g} / \mathrm{MJ}) \dagger$ & 1.4 & 0.3 & 1.4 & 0.3 \\
\hline $\mathrm{Ca}(\mathrm{mg} / \mathrm{d}) \dagger$ & $619 \cdot 1$ & $96 \cdot 6$ & $745 \cdot 4$ & $144 \cdot 0$ \\
\hline Phosphate $(\mathrm{mg} / \mathrm{d}) \dagger$ & $724 \cdot 1$ & 131.5 & $872 \cdot 7$ & 257.4 \\
\hline
\end{tabular}

†Estimated from food composition tables using Prodi expert 4.502 software (Wissenschaftliche Verlagsgesellschaft GmbH, Stuttgart, Germany). isomalt was added to one diet and sucrose to the other diet. Isomalt and sucrose were included in sweet foods (marmalade, junket, yoghurt, biscuits, chocolate, puddings and candies) during the test periods. The test products were prepared and supplied by SUEDZUCKER AG (Mannheim/Ochsenfurt, Germany). The dose was increased slowly from $5 \mathrm{~g} / \mathrm{d}$ to $30 \mathrm{~g} / \mathrm{d}$ in the first week of each test phase. Breakfast, morning snack, lunch, afternoon snack and dinner were provided with each diet. A $7 \mathrm{~d}$ rotating menu including ready-to-eat foods (Eismann TiefkühlHeimservice, Mettmann, Germany) was used. Meals were weighted and packed in the university hospital's dietetic kitchen. All meals were given to the subjects to be eaten at home. Additional food was not allowed, the volunteers were asked to consume the delivered portions completely. Food was given to the volunteers daily in the medical clinic by the study nutritionist. During these visits volunteers were asked by the study nutritionist about possible effects related to the diet or collecting of faeces and urine and were asked to return test meals of food not consumed. This regular contact was maintained to ensure volunteers' compliance. Body weight was measured at entry and then at daily intervals in the first week and thereafter at weekly intervals in both phases. When significant weight loss $(>2 \mathrm{~kg})$ over the course of the study was noted, the volunteers received a fibrefree formula diet (Biosorb; Pfrimmer Nutricia, Erlangen, Germany) to meet energy requirement. Water, tea and coffee were allowed ad libitum. Alcohol consumption was restricted to $500 \mathrm{ml}$ of beer or $250 \mathrm{ml}$ of wine per week. Sugar-free soft drinks were restricted to $500 \mathrm{ml}$ daily. The macronutrient composition of the diet was calculated with Prodi expert 4.502 software (Wissenschaftliche Verlagsgesellschaft $\mathrm{GmbH}$, Stuttgart, Germany). The intakes of $\mathrm{Ca}$ and dietary fibre were estimated on the basis of available data from food composition tables.

The volunteers kept a daily record of subjective intestinal parameters, stool frequency and stool consistency during the two 4-week study periods. Abdominal distension, flatulence, abdominal pain and nausea were scored on semi-quantitative scales from 0 (absent) to 3 (severe). Stool consistency was also scored from 1 (hard) to 4 (watery).

Twenty-four hour urine collections were obtained at the start and at weekly intervals in both phases. Venous blood was 
collected on the morning before and after each test period following a $12 \mathrm{~h}$ fast, and analysed for routine biochemical parameters and blood lipid status in the central laboratory of the University of Würzburg. In addition, tests for the assessment of renal and liver function, blood glucose, electrolytes, blood coagulation tests (prothrombin time and partial thromboplastin time) and complete blood count were performed. Serum and plasma samples for the determination of NEFA, leptin, fructosamine, oxidised LDL and remnant-like particle cholesterol (RLP-C) were stored at $-80^{\circ} \mathrm{C}$ until further analysis.

\section{Mean transit time and stool weight}

Mean transit time was measured from day 21 to day 24 of each study period using the single-stool method of Cummings \& Wiggins (1976) and radiopaque markers (P \& A Mauch, Münchenstein, Switzerland).

From day 24 to day 28 of each study period, stools were collected for quantitative assessment. Each stool was collected separately, frozen in the laboratory freezer and stored at $-25^{\circ} \mathrm{C}$. After completion of the study stool samples were thawed, and stool wet weight and faecal $\mathrm{pH}$ value were recorded. Five-day stool collections were pooled using a grinder. Faecal dry weight was measured after lyophilisation (Gamma IA apparatus; Christ, Osterode, Germany) of an aliquot to a constant weight.

\section{Determination of mannitol in urine}

Urine samples were filtered through a $0.45 \mu \mathrm{m}$ membrane and injected directly without dilution into a high-performance liquid chromatograph (HP 1100; Agilent Böblingen, Germany) equipped with an autosampler, column oven and refractive index detector. The separation was performed using a column (HPX-87C, $300 \mathrm{~mm} \times 7.8 \mathrm{~mm}$; Biorad Hercules, CA, USA) filled with cation-exchange resin in the $\mathrm{Ca}^{2+}$ form and purified water (HPLC-grade) at elevated temperature $\left(80^{\circ} \mathrm{C}\right)$ as eluent. Injection volume was $20 \mu \mathrm{l}$ and flow rate $0.5 \mathrm{ml} / \mathrm{min}$. Mannitol in the samples was quantified by comparison of peak areas according to the external standard method.

\section{Calcium and phosphate in urine and faeces}

The volumes of the $24 \mathrm{~h}$ urine collections were measured and aliquots were stored at $-25^{\circ} \mathrm{C}$ until analysis. $\mathrm{Ca}$ and phosphate analyses from urine samples were performed using colorimetric tests. Faecal $\mathrm{Ca}$ and phosphate were measured by flame photometry and ion-exchange chromatography, respectively. Apparent balances of $\mathrm{Ca}$ and phosphate were estimated by calculation: apparent balance $=$ intake - renal excretion - faecal excretion .

Blood lipids, apolipoproteins, lipoprotein (a), oxidised LDL and remnant-like particles

Cholesterol, triacylglycerols, HDL cholesterol and LDL cholesterol in serum were determined using colorimetric enzyme kits (Roche Diagnostics, Mannheim, Germany). Apolipoproteins A-1, A-2, B 100 and lipoprotein (a) were measured immuno-turbidimetrically (Roche Diagnostics). RLP-C was analysed in plasma probes using the RLP-Cholesterol Immunoseparation Assay (Schreuder et al. 2001). Oxidised LDL in plasma was analysed using an ELISA kit (Mercodia, Uppsala, Sweden).

\section{NEFA, leptin and fructosamine in serum}

NEFA and fructosamine were determined by enzymatic colorimetric assay kit (Boehringer, Mannheim, Germany). Leptin concentration was measured with an RIA kit (Mediagnost, Reutlingen, Germany). Leptin levels are expressed as genderand BMI-adjusted standard deviation (SD) scores according to Scholz et al. (1996).

\section{Statistical analysis}

Values are given as means with their standard errors. The nonparametric Wilcoxon rank-sum test for paired data was used for comparisons. For repeated measurements (renal $\mathrm{Ca}$, phosphate excretion), Friedman repeated-measures ANOVA on ranks was first performed to test for any significant differences among groups. When significant, the Tukey test was used to determine the specific differences between means. Differences were considered to be significant at $P<0 \cdot 05$. Statistical analyses were carried out using SigmaStat for Windows version 2.03 (SPSS Inc., Chicago, IL, USA).

\section{Results}

Subjects

Mean BMI and mean body weight did not differ in the two study periods. There was a slight and similar reduction in body weight during both diet periods $(-1.2$ (SE 0.3$) \mathrm{kg}$ with isomalt and -1.2 (SE 0.2) $\mathrm{kg}$ with sucrose). Subjective intestinal parameters were usually mild to moderate and in no case led to discontinuation of the study. On a semi-quantitative scale from 0 (absent) to 3 (severe), the average score of distension was 0.7 in the sucrose and 1.8 in the isomalt phase $(P=0.002)$. In each test phase pain and nausea were rare events. In conclusion, the daily consumption of $30 \mathrm{~g}$ isomalt was well tolerated.

\section{Compliance}

Urinary mannitol excretion was used to assess isomalt intake of the volunteers. Mean renal mannitol excretion was significantly higher with isomalt compared with sucrose at each time point of the respective study phase (Table 2) . Furthermore, for each volunteer the urinary mannitol excretion was higher with isomalt than sucrose (not shown).

\section{Routine blood parameters}

Routine biochemical and standard clinical parameters for the assessment of renal and liver function, clotting (prothrombin time and partial thromboplastin time) and complete blood count were not influenced by isomalt consumption and were comparable in both test phases. Significant differences were only noted on platelet counts (isomalt: $250.0(\mathrm{SE} 13.8) \times 10^{3} / \mu \mathrm{l} v$. sucrose: $242.8($ SE 12.8$\left.) \times 10^{3} / \mu 1 ; P=0.012\right)$ and glutamate-oxaloacetate transaminase (isomalt: 9.5 (SE 0.4 ) U/l $v$. sucrose: 8.3 (SE 0.4) $\mathrm{U} / 1 ; P=0 \cdot 007)$. Both parameters remained in the normal range in both periods. 
Table 2. Urinary mannitol excretion of nineteen healthy volunteers following consumption of either $30 \mathrm{~g}$ isomalt/d or $30 \mathrm{~g}$ sucrose/d for 4 weeks (Mean values with their standard error)

\begin{tabular}{llllll}
\hline & \multicolumn{2}{c}{ Isomalt mannitol $(\mathrm{g} / \mathrm{d})$} & & \multicolumn{2}{c}{ Sucrose mannitol $(\mathrm{g} / \mathrm{d})$} \\
\cline { 2 - 3 } \cline { 5 - 6 } Week & Mean & SE $(n 19)$ & & Mean & SE $(n 19)$ \\
\hline 0 & 0.23 & 0.03 & & 0.38 & 0.09 \\
1 & $0.98^{\star \star *}$ & 0.13 & & 0.20 & 0.02 \\
2 & $0.98^{\star * *}$ & 0.12 & & 0.21 & 0.02 \\
3 & $0.78^{*}$ & 0.08 & & 0.21 & 0.02 \\
4 & $1.09^{*}$ & 0.18 & & 0.20 & 0.03 \\
\hline
\end{tabular}

Mean values were significantly different from those of the sucrose group (Wilcoxon test for paired data): ${ }^{\star} P<0.05,{ }^{\star \star \star} P<0.001$.

In the isomalt group, mean value at week 0 was significantly different from that at week 4 (Wilcoxon test for paired data): $P<0.001$

\section{Blood lipids}

Values for blood lipids are shown in Table 3. Consumption of isomalt had no significant effect on total cholesterol, HDL cholesterol, LDL cholesterol, triacylglycerols, apo A-2, apo $\mathrm{B}_{100}$, lipoprotein (a), oxidised LDL or RLP-C. Apo A-1 levels were significantly lower after intervention with isomalt compared with sucrose.

In the hyperlipidaemia subgroup all parameters of blood lipids including apo A-1 and LDL:HDL ratio were comparable. A slight reduction of cholesterol levels (265.7 (SE 17.5) v. 232.0 (SE 20.5) $\mathrm{mg} / \mathrm{dl} ; P=0.063)$ and lower levels of apo $\mathrm{B}_{100}(132.2$ (SE 11.3) v. $115.0(\mathrm{SE} 11.0) \mathrm{mg} / \mathrm{dl} ; P=0.063)$ and LDL cholesterol $(177.0$ (SE 18.2) v. 150.0 (SE 20.9) $\mathrm{mg} / \mathrm{dl} ; P=0 \cdot 156)$ were noted within the isomalt period compared with baseline.

\section{NEFA, leptin and fructosamine}

Isomalt consumption had no significant effect on NEFA, leptin and fructosamine as compared with sucrose (Table 3).

Table 3. Blood lipids, NEFA, leptin and fructosamine levels of nineteen healthy volunteers following consumption of either $30 \mathrm{~g}$ isomalt/d or $30 \mathrm{~g}$ sucrose/d for 4 weeks

(Mean values with their standard error)

\begin{tabular}{|c|c|c|c|c|}
\hline & \multicolumn{2}{|c|}{ Isomalt } & \multicolumn{2}{|c|}{ Sucrose } \\
\hline & Mean & SE $(n 19)$ & Mean & SE $(n 19)$ \\
\hline Cholesterol (mg/dl) & $197 \cdot 7$ & $10 \cdot 3$ & $187 \cdot 7$ & $11 \cdot 7$ \\
\hline LDL cholesterol (mg/dl) & $123 \cdot 7$ & 9.9 & $110 \cdot 4$ & $10 \cdot 5$ \\
\hline HDL cholesterol (mg/dl) & $50 \cdot 6$ & $3 \cdot 2$ & 51.9 & $3 \cdot 2$ \\
\hline LDL:HDL & $2 \cdot 6$ & 0.3 & $2 \cdot 2$ & 0.2 \\
\hline Triacylglycerols (mg/dl) & $118 \cdot 3$ & $17 \cdot 3$ & $117 \cdot 6$ & $23 \cdot 6$ \\
\hline Apo A-1 (mg/dl) & $143 \cdot 6^{*}$ & $5 \cdot 4$ & $146 \cdot 7$ & $4 \cdot 8$ \\
\hline Apo A-2 (mg/dl) & 33.2 & 1.4 & $33 \cdot 1$ & 1.4 \\
\hline Apo $B_{100}(\mathrm{mg} / \mathrm{dl})$ & $91 \cdot 0$ & $7 \cdot 0$ & $88 \cdot 3$ & $6 \cdot 7$ \\
\hline Lipoprotein (a) (mg/dl) & $24 \cdot 1$ & $7 \cdot 3$ & $24 \cdot 6$ & $7 \cdot 7$ \\
\hline Oxidised LDL (U/I) & $47 \cdot 1$ & 3.6 & $43 \cdot 9$ & 3.2 \\
\hline RLP-C (mmol/l) & 0.30 & 0.04 & 0.34 & 0.07 \\
\hline Men & 0.30 & 0.06 & 0.30 & 0.04 \\
\hline Women & 0.31 & 0.05 & 0.37 & 0.11 \\
\hline NEFA (mmol/l) & $123 \cdot 7$ & $9 \cdot 9$ & $110 \cdot 4$ & $10 \cdot 5$ \\
\hline Leptin (SD score) & -0.076 & 0.23 & -0.271 & 0.27 \\
\hline Fructosamine $(\mu \mathrm{mol} / \mathrm{l})$ & $207 \cdot 7$ & $16 \cdot 0$ & 213.5 & $10 \cdot 1$ \\
\hline
\end{tabular}

RLP-C, remnant-like particle cholesterol.

Mean values were significantly different from those of the sucrose group (Wilcoxon test for paired data): ${ }^{*} P<0.05$.
Calcium and phosphate in urine and faeces

Daily urine volume, daily $\mathrm{Ca}$ excretion and phosphate concentration in urine were comparable in both phases at all intervals. Neither faecal excretion nor apparent balance and absorption of $\mathrm{Ca}$ and phosphate were affected by isomalt consumption, being comparable in both phases (Table 4) and very variable on an individual level (Fig. 2).

\section{Stool parameters}

As shown in Table 5, stool consistency and mean transit time were similar in both periods. Stool frequency was moderately, but significantly, higher in the isomalt period $(P<0.006)$. The moderate increases in wet weight $(12 \%)$, dry weight $(15 \%)$ and faecal water content $(11 \%)$ did not reach significance.

\section{Discussion}

The aim of the present study was to examine the impact of regular isomalt consumption on physiological and metabolic markers, particularly with regard to Western diseases like CVD, obesity and diabetes, as well as on homeostasis of $\mathrm{Ca}$ and phosphate.

In this study, isomalt was consumed within a controlled diet in the form of a variety of foods like jam, biscuits, puddings, candies and chocolate. Isomalt and the isomalt products used in this study were well accepted and $30 \mathrm{~g} / \mathrm{d}$ was well tolerated, confirming previous conclusions (Livesey, 2001). Since a relatively wide range of sweet foods was offered, a monotonous diet could be prevented.

Mannitol excretion was used to assess compliance of regular isomalt intake. After partial hydrolysis of isomalt, a part of the resulting mannitol is absorbed and undergoes renal elimination without degradation. Urinary mannitol was intended as a qualitative marker of compliance. Theoretically, with $30 \mathrm{~g}$ isomalt/d and assuming a $10 \%$ hydrolysis of GPM (Livesey, 2003), approximately $0.75 \mathrm{~g}$ of mannitol might be absorbed and excreted

Table 4. Calcium and phosphate homeostasis in nineteen healthy volunteers following consumption of either $30 \mathrm{~g}$ isomalt/d or $30 \mathrm{~g}$ sucrose/d for 4 weeks (Mean values with their standard error)

\begin{tabular}{|c|c|c|c|c|}
\hline & \multicolumn{2}{|c|}{ Isomalt } & \multicolumn{2}{|c|}{ Sucrose } \\
\hline & \multicolumn{2}{|c|}{ Mean SE $(n 19)$} & \multicolumn{2}{|c|}{ Mean SE $(n 19)$} \\
\hline \multicolumn{5}{|l|}{ Faecal Ca } \\
\hline ( $\mu \mathrm{mol} / \mathrm{g}$ faeces) & $126 \cdot 1$ & $6 \cdot 0$ & $133 \cdot 2$ & $9 \cdot 6$ \\
\hline$(\mathrm{mmol} / \mathrm{d})$ & 13.5 & 0.9 & $12 \cdot 6$ & $1 \cdot 1$ \\
\hline \multicolumn{5}{|l|}{ Urinary $\mathrm{Ca}$} \\
\hline (mmol/l urine) & 3.5 & 0.5 & $3 \cdot 1$ & 0.5 \\
\hline$(\mathrm{mmol} / \mathrm{d})$ & $5 \cdot 1$ & 0.7 & $4 \cdot 2$ & $0 \cdot 7$ \\
\hline$\Sigma \mathrm{Ca}$ excretion $(\mathrm{mmol} / \mathrm{d})$ & $18 \cdot 5$ & $1 \cdot 2$ & $17 \cdot 1$ & 1.5 \\
\hline Apparent Ca balance $(\mathrm{mmol} / \mathrm{d})$ & -1.8 & $1 \cdot 3$ & -0.4 & 1.5 \\
\hline Apparent Ca absorption (\%) & 18 & 6 & 23 & 7 \\
\hline \multicolumn{5}{|l|}{ Faecal phosphate } \\
\hline (mg/g faeces) & $3 \cdot 3$ & 0.4 & $3 \cdot 4$ & 0.3 \\
\hline$(\mathrm{mg} / \mathrm{d})$ & 353 & 42 & 310 & 26 \\
\hline Urinary phosphate (mg/d) & 809 & 92 & 817 & 100 \\
\hline$\Sigma$ phosphate excretion $(\mathrm{mg} / \mathrm{d})$ & 1161 & 92 & 1127 & 105 \\
\hline Apparent phosphate balance $(\mathrm{mg} / \mathrm{d})$ & -382 & 92 & -349 & 101 \\
\hline Apparent phosphate absorption (\%) & 54 & 6 & 60 & 4 \\
\hline
\end{tabular}

There were no significant differences between mean values in the iosmalt and sucrose groups (Wilcoxon test for paired data or Friedman test for urine data). 




Fig. 2. Apparent calcium balance $(\mathrm{mmol} / \mathrm{d})$ of nineteen healthy volunteers following consumption of either $30 \mathrm{~g}$ isomalt/d or $30 \mathrm{~g}$ sucrose/d for 4 weeks.

in urine. This is close to the average amount of $0.8 \mathrm{~g}$ urinary mannitol/d found within the isomalt period. During the isomalt period, mannitol excretion was significantly higher than at baseline and the levels measured in the sucrose phase, showing qualitatively the compliance.

However, mannitol was also detectable in urine samples at baseline as well as during the sucrose period. This may be due to the natural occurrence of mannitol in plant foods like olives and celery (Laker et al. 1982). Due to a dilution effect (daily urine volume up to 51 ) one volunteer had very low mannitol levels in all test periods. This subject was not suspected to be non-compliant or to have a malabsorption syndrome (adult coeliac disease was excluded by clinical history and a negative tissue transglutaminase antibody test). The individual data for all volunteers showed higher mannitol excretion in the test phase with isomalt compared with the sucrose period. Thus, the determination of urinary mannitol excretion is a reliable qualitative marker of isomalt intake for intra-individual comparisons.

One aspect of the current study was to examine the effects of isomalt consumption on metabolic parameters such as lipid metabolism. In the current study, triacylglycerol levels as well as risk parameters for CVD like LDL cholesterol, oxidised LDL and RLP-C were not affected by isomalt, including in hyperlipidaemic volunteers. Minor differences in blood lipids were observed between both interventions related to lower apo A-1

Table 5. Stool parameters in nineteen healthy volunteers following consumption of either $30 \mathrm{~g}$ isomalt/d or $30 \mathrm{~g}$ sucrose/d for 4 weeks (Mean values with their standard error)

\begin{tabular}{|c|c|c|c|c|}
\hline & \multicolumn{2}{|c|}{ Isomalt } & \multicolumn{2}{|c|}{ Sucrose } \\
\hline & Mean & SE $(n 19)$ & Mean & SE $(n 19)$ \\
\hline Stool frequency $(/ d)$ & $1 \cdot 3^{\star \star}$ & 0.1 & $1 \cdot 1$ & 0.1 \\
\hline Stool consistency† & 1.9 & 0.1 & $1 \cdot 8$ & 0.1 \\
\hline Stool wet weight $(\mathrm{g} / \mathrm{d})$ & $110 \cdot 9$ & $9 \cdot 1$ & $99 \cdot 1$ & $8 \cdot 8$ \\
\hline \multicolumn{5}{|l|}{ Stool dry weight } \\
\hline$(g / d)$ & $27 \cdot 7$ & 1.9 & $24 \cdot 2$ & $1 \cdot 8$ \\
\hline$(\%)$ & $25 \cdot 9$ & $1 \cdot 2$ & $25 \cdot 6$ & $1 \cdot 2$ \\
\hline \multicolumn{5}{|l|}{ Stool water } \\
\hline$(g / d)$ & 83.0 & $7 \cdot 7$ & 74.9 & $7 \cdot 3$ \\
\hline$(\%)$ & $74 \cdot 1$ & $1 \cdot 2$ & 74.4 & $1 \cdot 2$ \\
\hline Mean transit time $(\mathrm{h})$ & $52 \cdot 0$ & 4.5 & 54.5 & $6 \cdot 2$ \\
\hline
\end{tabular}

Mean values were significantly different from those of the sucrose group (Wilcoxon test for paired data): ${ }^{\star \star} P<0.01$.

† Volunteers scored stool consistency from 1 (hard) to 4 (watery). concentrations with isomalt. In volunteers with hyperlipidaemia the LDL:HDL ratio was constant. In conclusion, chronic isomalt intake does not seem do have relevant adverse effects on blood lipids and high-risk parameters of CVD, especially in subjects with hyperlipidaemia.

Isomalt is of potential interest to diabetics because of its low glycaemic effects. Consumption of milk chocolate containing $70 \mathrm{~g}$ isomalt results in a lower postprandial plasma glucose response compared with chocolate containing sucrose. Reduction of glycation products like fructosamine and glycated $\mathrm{Hb}(\mathrm{HbAlc})$ is associated with delay in the manifestation of diabetic lesions. Thus, possible benefits for diabetics need to be investigated further in long-term studies.

In the present study, $\mathrm{Ca}$ and phosphate homeostasis was not affected by chronic isomalt intake. Apparent $\mathrm{Ca}$ and phosphate balances were comparable in both treatments. Daily Ca excretion was not altered by isomalt.

In earlier studies, laxative effects (typically understood as one or more watery stools or more than three stools per day) of single high doses of isomalt were reported. However, in these studies, the pattern of consumption (a high dose of isomalt after a period of fasting) did not reflect typical consumption behaviour (Marteau \& Flourie, 2001). Little is known about bowel function under regular isomalt intake in common foods, divided into five daily meals. In the present study, several stool and functional parameters were used to evaluate bowel function.

Mean transit time is usually inversely related to stool weight (Burkitt et al. 1972). However, there is evidence that this correlation applies to high initial mean transit times only (Spiller et al. 1980). It has been shown that the longer the initial transit time, the more pronounced the shortening of the transit time during fibre supplementation (Cummings et al. 1978). However, despite higher stool weights, a markedly longer mean transit time was observed in healthy young volunteers during starch malabsorption induced by acarbose (Scheppach et al. 1988) or during supplementation with a controlled diet including resistant starch over 4 weeks (Hylla et al. 1998). In the present study, healthy volunteers had normal initial mean transit times that were not affected during the course of the intervention.

No significant differences in stool weights were observed in either test period. The study diet was designed as a 'Western diet' with low fibre content. Faecal wet weight was in accordance with the data of other authors who measured faecal excretion under a common European diet (Rendtorff \& Kashgarian, 1967; Burkitt et al. 1974). However, with isomalt, mean wet stool weight was increased by $12 \%$ and mean dry stool weight by $15 \%$ (NS). NSP and low-digestible carbohydrates raise stool weight due to increased water content as well as an increased bacterial mass (Burkitt et al. 1972; Hillman et al. 1983; Cummings et al. 1992). The modest effects on faecal parameters, i.e. increase in faecal wet and dry weight, is in good agreement with the magnitude of effects seen for other non-digestible fermentable carbohydrates (e.g. Alles et al. 1996, 1999; Brighenti et al. 1999). Furthermore, it should be taken into consideration that the majority of our volunteers were young and healthy and did not suffer from constipation. Investigations in elderly constipated men showed that after supplementation with low-digestible oligosaccharides over $30 \mathrm{~d}$, an increase of stool weight, defecation frequency and a reduction of enema use occurred. The increase in stool output was mainly attributed to an increased bacterial mass (Chen et al. 2001). 
In the present study, a moderate increase in stool frequency during the test period with isomalt in the physiological range was observed. Stool consistency and stool water concentrations, as indicators for loose stools, were not affected. Regarding chronic functional constipation, which is very common in Western countries, mild laxative effects could be beneficial for consumer health and well-being.

Our data suggest that the consumption of isomalt does not impair metabolic function or induce hypercalciuria. High-risk parameters of arteriosclerosis like LDL cholesterol, oxidised LDL and RLP-C in normolipidaemic or hyperlipidaemic volunteers were not affected. In addition, results obtained for parameters of bowel function indicate that isomalt could improve bowel function in constipated persons.

In conclusion, the present study confirmed that isomalt is well tolerated when consumed for a longer period and does not impair physiological and metabolic parameters.

\section{Acknowledgements}

We thank Elisabeth Kelber and Kerstin Backhaus for excellent help; Dierk Martin and Sonja Ehrhardt of SUEDZUCKER AG, Obrigheim/Pfalz, Germany for measuring mannitol, Ca and phosphate; Sabine Weber and Margit Arenz of SUEDZUCKER AG for development and preparation of the test products; the central laboratory of the University of Würzburg, Germany for routine blood and urine analyses; Margarete Röder of the University of Wuerzburg for measuring oxidised LDL; Geesje Dallinga-Thie of the University of Utrecht, The Netherlands for measuring RLP-C; and Ruth Hoppe and staff of the dietetic kitchen for kind co-operation.

\section{References}

Alles MS, Hautvast JG, Nagengast FM, Hartemink R, Van Laere KMJ \& Jansen JBMJ (1996) Fate of fructo-oligosaccharides in the human intestine. Br J Nutr 76, 211-221.

Alles MS, de Roos NM, Bakx JC, van de Lisdonk E, Zock PL \& Hautvast GA (1999) Consumption of fructooligosacchrides does not favorably affect blood glucose and serum lipid concentrations in patients with type 2 diabetes. Am J Clin Nutr 69, 64-69.

Bär A (1990) Factorial calculation model for the estimation of the physiological caloric value of polyols. In Proceedings of the International Symposium on Caloric Evaluation of Carbohydrates, pp. 209-257 [N Hosoxa, editor]. Tokyo: Research Foundation for Sugar Metabolism.

Brighenti F, Casiraghi MC, Canzi E \& Ferrari A (1999) Effect of consumption of a ready-to-eat breakfast cereal containing inulin on the intestinal milieu and blood lipids in healthy young male volunteers. Eur J Clin Nutr 53, 726-733.

Burkitt DP, Walker ARP \& Painter NS (1972) Effect of dietary fibre on stools and transit times, and its role in the causation of disease. Lancet 2, 1408-1411.

Burkitt DP, Walker AR \& Painter NS (1974) Dietary fiber and disease. JAMA 229, 1068-1074.

Chen HL, Lu YH, Lin JJ \& Ko LY (2001) Effects of isomalto-oligosaccharides on bowel functions and indicators of nutritional status in constipated elderly men. J Am Coll Nutr 20, 44-49.

Cummings JH \& Wiggins HS (1976) Transit through the gut measured by analysis of a single stool. Gut 17, 219-223.
Cummings JH, Branch WJ, Jenkins DJA, Southgate DAT, Houston H \& James WPT (1978) Colonic response to dietary fibre from carrot, cabbage, apple, bran, and guar gum. Lancet 1, 5-9.

Cummings JH, Bingham SA, Heaton KW \& Eastwood MA (1992) Fecal weight, colon cancer risk, and dietary intake of nonstarch polysaccharides (dietary fiber). Gastroenterology 103, 1783-1789.

Dills WL (1989) Sugar alcohols as bulk sweeteners. Annu Rev Nutr 9, $161-186$.

Gee JM, Cooke D, Gorick S, Wortley GM, Greenwood RH, Zumbe A \& Johnson IT (1991) Effects of conventional sucrose-based, fructosebased and isomalt-based chocolates on postprandial metabolism in non-insulin-dependent diabetics. Eur J Clin Nutr 45, 561-566.

Gehring F \& Karle EJ (1981) [Sweetening agent, Palatinit under specific consideration as to microbiological and caries-prophylactic aspects]. Z Ernahrungswiss 20, 96-106.

Hillman L, Peters S, Fisher A \& Pomare EW (1983) Differing effects of pectin, cellulose and lignin on stool $\mathrm{pH}$, transit time and weight. $\mathrm{Br}$ J Nutr 50, 189-195.

Hütter R, Böswart F \& Irsigler K (1993) [Insulinverbrauch von Typ-I-Diabetikern nach oraler Gabe von Isomalt]. Akt Ernähr 18, 149-154.

Hylla S, Gostner A, Dusel G, Anger H, Bartram HP, Christl SU, Kasper H \& Scheppach W (1998) Effects of resistant starch on the colon in healthy volunteers: possible implications for cancer prevention. Am $J$ Clin Nutr 67, 136-142.

Koutsou GA, Storey DM, Lee A, Zumbe A, Flourie B, leBot Y \& Olivier $P$ (1996) Dose-related gastrointestinal response to the ingestion of either isomalt, lactitol or maltitol in milk chocolate. Eur J Clin Nutr 50, 17-21.

Laker MF, Bull HJ \& Menzies IS (1982) Evaluation of mannitol for use as a probe marker of gastrointestinal permeability in man. Eur J Clin Invest 12, 485-491.

Lee A, Wils D, Zumbe A \& Storey DM (2002) The comparative gastrointestinal responses of children and adults following consumption of sweets formulated with sucrose, isomalt and lycasin HBC. Eur J Clin Nutr 56, 755-764.

Life Science Research Office (1994) The Evaluation of the Energy of Certain Sugar Alcohols used as Food Ingredients. Bethesda, MD: Life Science Research Office, Federation of the American Society for Experimental Biology.

Livesey G (2001) Tolerance of low-digestible carbohydrates: a general view. Br J Nutr 85, S7-S16.

Livesey G (2003) Health potential of polyols as sugar replacers, with emphasis on low glycaemic properties. Nutr Res Rev 16, $163-191$.

Livesey G, Buss D, Coussement P, Edwards DG, Howlett J, Jonas DA, Kleiner JE, Müller D \& Sentko A (2000) Suitability of traditional energy values for novel foods and food ingredients. Food Control 11, 249-289.

Marteau P \& Flourie B (2001) Tolerance to low-digestible carbohydrates: symptomatology and methods. Br J Nutr 85, Suppl. 1, S17-S21.

Petzoldt R, Lauer P, Spengler M \& Schoffling K (1982) [Palatinite in type II diabetics. Effect on blood-glucose, serum-insulin, C-peptide and free fatty acids]. Dtsch Med Wochenschr 107, 1910-1913.

Rendtorff RC \& Kashgarian M (1967) Stool patterns of heathy adult males. Dis Colon Rectum 10, 222-228.

Scheppach W, Fabian C, Ahrens F, Spengler M \& Kasper H (1988) Effect of starch malabsorption on colonic function and metabolism in humans. Gastroenterology 95, 1549-1555.

Scheppach W, Luehrs H \& Menzel T (2001) Beneficial health effects of low-digestible carbohydrate consumption. Br J Nutr 85, Suppl. 1, S23-S30.

Scholz GH, Englaro P, Thiele I, Scholz M, Klusmann T, Kellner K, Rascher W \& Blum WF (1996) Dissociation of serum leptin concentration and body fat content during long term dietary intervention in obese individuals. Horm Metab Res 28, 718-723.

Schreuder PCNJ, Twickler TB, Wang T, Nakajima K, Erkelens DW \& Dallinga-Thie GM (2001) Isolation of remnant particles by 
immunoseparation: a new approach for investigation of postprandial lipoprotein metabolism in normolipidemic subjects. Atherosclerosis 157, 145-150.

Spiller GA, Chernof MC, Hill RA, Gates JE, Nassar JJ \& Shipley EA (1980) Effect of purified cellulose, pectin, and a low-residue diet on fecal volatile fatty acids, transit time, and fecal weight in humans. Am J Clin Nutr 33, 754-759.
Storey DM, Lee A \& Zumbe A (2002) The comparative gastrointestinal response of young children to the ingestion of $25 \mathrm{~g}$ sweets containing sucrose or isomalt. Br J Nutr 87, 291-297.

Zumbe A \& Brinkworth RA (1992) Comparative studies of gastrointestinal tolerance and acceptability of milk chocolate containing either sucrose, isomalt or sorbitol in healthy consumers and type II diabetics. Z Ernahrungswiss 31, 40-48. 